\title{
Review of Julian Reiss's Philosophy of economics: a contemporary introduction. Routledge, 2013, 352 pp.
}

\author{
HAROLD KINCAID \\ University of Cape Town
}

Writing a textbook on philosophy of economics presents some hard challenges. Neither philosophy nor economics is sufficiently defined and circumscribed to make an overview easy. The nature of philosophy is currently quite contested. The naturalism movement exemplified by Quine now competes with a very traditional, conceptual-analysis trend that gives limited place to science (and thus by implication to economics). Philosophy of science-which is at the heart of naturalismhas mostly moved away from broad issues such as the nature of confirmation or explanation to a close engagement with specific sciences, in large part because it seems not all that much can be said about explanation, confirmation and the like in the abstract. Economics has grown tremendously in terms of tools and topics. It is no longer possible (if it ever was) to identify the core of economics with static general equilibrium theory. Game theory, new institutional economics, and experimental economics-all applied to an increasingly wide range of phenomena-make it nearly impossible to talk about philosophical issues in the field as a whole.

Aside from these problems, a textbook in philosophy of economics confronts a problem of audience. Is the target philosophy students? If it is, then how is philosophy of economics supposed to be done for students without much knowledge of economics, especially if the goal is to do philosophy of science close to the science itself? If the target is economics students (though I doubt that more than a handful of economics departments offer such a course-mine does not), what distinguishes the course from an ordinary economics course on whatever part of economics is considered?

Julian Reiss's new book reflects these inevitable tensions but largely does an admirable job of confronting them. Reiss deals with the ever larger scope and available tools of economics and with the philosophy of science imperative to engage closely with the science by covering an enormous range of work in economics in a fair amount of detail, as well 
as recent relevant general philosophy of science and normative theory. His general strategy is to explain some piece of economics in some detail, some relevant philosophy of science or ethical and political theory if needed, and then present something of a critical analysis of the economics and/or the philosophy. The relative emphases on these components vary from chapter to chapter. For example, some chapters are content to present the economics and the issues raised while others argue in detail for specific conclusions.

An enormous range of topics are included in this book, with a full one third of the book covering ethical, social, and political issues. Among the chapters are:

- A thorough presentation of standard decision theory;

- A presentation of rational-choice game theory;

- A survey of current views on causality and mechanisms in philosophy;

- A presentation of different approaches to idealized models;

- A discussion of the complexities of measurement in economics;

- An interesting discussion of present day emphasis in economics on randomized controlled trials and natural experiments;

- A catalogue of uses that economic experiments might serve and the kinds of difficulties they face;

- A discussion of accounts of well-being and distributive justice;

- Arguments for libertarian or "soft" paternalism.

The end result is that Reiss's book allows for tremendous flexibility in designing different courses. For example, it would be easy to develop courses that involved nearly all philosophy of science issues or ones that were mostly normative issues around economics, with any mix in between. I also think Reiss's text can work as the sole book for a course or be used along with other articles to expand on the discussion Reiss provides. The book certainly provides much material that can usefully be expanded upon in lectures. There is nothing out there that rivals it for teaching a course on philosophy of economics, and it would be a good tool for certain kinds of courses in political philosophy or philosophy and public policy.

While Reiss clearly intends his work to be a textbook in the field (there are useful study questions and chapter summaries), he cannot help making some substantive claims in philosophy of economics. 
Many of these are compelling. For instance, Reiss argues convincingly that normative values are involved in fundamental ways in making basic economic measurements. He works through the details of various ways of constructing the consumer price index, for example, and identifies the value assumptions involved. His conclusion is not that such measurements are worthless but rather that the particular value assumptions involved should be made explicit.

This is the kind of philosophy of economics I like. It is close to the details and recognizes the variation on the ground-the different ways theories, models, and so forth, are applied. It does not rely on traditional philosophical methods of conceptual analysis with necessary and sufficient conditions tested against what we would say or our intuitions. It does use the traditional philosophical skills of careful separation of theses and arguments to clarify the science and perhaps to contribute to its betterment.

Where I disagree with Reiss's substantive claims in philosophy of economics is when he drops this approach and returns to traditional philosophical methods of conceptual analysis. He does so on several occasions. I will discuss two: his treatment of rational choice theory and of game theory.

Reiss takes microeconomics to be based on and to be defending a normative account of rationality. He also takes the less ambitious approach of revealed preference theory as an account of the notions of choice and preference, where 'account' here means supplying individually necessary and jointly sufficient conditions for fundamental concepts. Assuming that economics is committed to such goals, he is then able to identify counterexamples where economists' accounts do not capture standard intuitions about rationality and choice.

Reiss is not unusual in looking at microeconomics in this way (see Hausman 2012), and maybe some economists do so as well. However, there are other ways to understand what economists do that do not commit them to the project of specifying a general theory of rationality or to take revealed preference theory as defining choice and preference. Good science often develops concepts that have no clear connection or basis to those of common sense and trying to force science to have those connections can be a positive hindrance to scientific advancement (see Ross, et al. 2013). There is a plausible history of economic thinking that sees developments in the 20th century as moving farther and farther away from ordinary common 
sense and folk psychological notions of choice and rationality towards quite distinct notions that suit economists' purposes.

Those purposes have been above all to explain aggregate market supply and demand phenomena (see Kincaid 1996). Concepts of rationality and choice have thus been moulded to that end. Rather than trying to provide a general theory or a definition of rationality or rational behaviour-which Ken Binmore (2011) points out is like trying to define life or conscious, which is unlikely to be helpful-the concern is to find constraints suitable for modelling aggregate behaviour. The standard requirements are made to identify consistent patterns of choice. It is an empirical question whether such patterns exist in aggregate market behaviour. Whether 'consistent patterns of choice' captures everything in common sense notions of rationality is beside the point. Something similar is true of revealed preference theory. By design it is not about the underlying processes behind choice, nor is it a theory of choice in the folk psychological sense. Revealed preference theory is about consistent behaviours that are sensitive to incentives. Behaviours combined with prices and budget constraints are designed to help understand aggregate market phenomena. Once again the kinds of counterexamples that Reiss cites showing that behaviours of this sort do not match our common sense notions of choice and preference are beside the point.

I am sure that identifying exactly what economists are up to with revealed preference theory is not an easy task. As mentioned above in my positive remarks about Reiss's discussion of the consumer price index, economists may invoke revealed preference theory for different purposes and with different understandings in different contexts. Those have to be sorted out with care, the clearest attempt to do so on my view being Don Ross's $(2011 ;$ 2012). Such sorting out requires precisely not confusing revealed preference theory with folk psychological notions.

A second place where Reiss's philosophy of economics is too traditional for me is in his discussion of game theory. The following quotation summarizes his view nicely:

Game theory, understood as a theory of rational decision-making, is thus highly problematic. The Nash equilibrium is ill-justified. Even if it were justified, it would solve few problems because most games have multiple Nash equilibria. Thus far, the refinement 
program has produced few results that can be defended from the point of view of rationality (p. 73).

What bothers me about this approach is that it dismisses a large body of empirical social science on general philosophical grounds, namely, that game theory cannot be defended as an instantiation of general principles of rationality.

There are many possible responses to Reiss's scepticism. First, it completely ignores evolutionary game theory-it is not even mentioned in the book-despite the fact that it has probably eclipsed rationalchoice game theory in economic applications. Evolutionary game theory obviously does not depend on a theory of rationality for its results and thus is not subject to Reiss's criticisms even if those criticisms are compelling for rational-choice game theory.

Moreover, Reiss's criticisms of rational-choice game theory are not convincing when it comes to uses of game theory as empirical science (whether they are compelling criticisms of the uses philosophers make of game theory is another issue). The goal in empirical applications is to use game theory as a modelling tool, not to develop an a-priori theory of rationality. Reiss claims that Nash equilibrium is unjustified. However, past supposed counterexamples to Nash equilibrium in the literature have been often shown to be implicitly invoking a different game than the one explicitly represented. Ken Binmore (1994) has shown this for standard alleged counterexamples. However, even if this were not the case, there are many applications of game theory where we know Nash outcomes result, regardless of whether being a Nash equilibrium is a necessary and sufficient condition of being rational. Of course evolutionary game theory is such a case, for evolutionary stable strategies are Nash outcomes. Furthermore, when given sufficient incentives and sufficient time to learn, experimental subjects find Nash outcomes even in bargaining games, widely thought to be the most difficult domain for successful game theory predictions (see Binmore 2007). They also do so when there are multiple Nash equilibria.

There are of course refinements to Nash equilibria and alternative equilibrium concepts. For example, one particularly important alternative is the notion of quantal response equilibria (QREs) which allow for equilibria around Nash points and which leave room for one sense of errors. In empirical work QREs allow for predictive success that a simple Nash equilibrium does not. So it is not a matter of which is the "right" equilibrium. Rather it is an empirical and modelling question 
about which notions fit the data best; there will not be one answer across all contexts.

I think there is no doubt that sometimes game theory works. Industrial organization, a vibrant area of microeconomics, is now almost entirely done using game theory tools. I would not want to dismiss that work carte blanche because of philosophical doubts that Nash equilibrium is rational. I would want to know how that work deals with problems of multiple equilibria, what solution concepts it uses and why, and so on. There is of course no guarantee that all applications are successful or believable. Yet that is a judgment that has to be made while looking at the full gory details of the applications. The philosophy of economics has to be closer to the economics itself than Reiss's discussion provides.

However, while I have some philosophical differences with the author, that adds rather than detracts from the book's value as a textbook. Reiss clearly takes stands on issues. Doing so makes for a much better textbook over one that just blandly rehearses different positions in debates. It is good that there are issues to argue with in his textbook.

\section{REFERENCES}

Binmore, Ken. 1994. Game theory and the social contract. Cambridge: MIT Press.

Binmore, Ken. 2007. Does game theory work?: the bargaining challenge. Cambridge: MIT Press.

Binmore, Ken. 2011. Rational decisions. Princeton: Princeton University Press.

Hausman, Daniel M. 2012. Preference, value, choice, and welfare. Cambridge: Cambridge University Press.

Kincaid, Harold. 1996. Philosophical foundations of the social sciences. Cambridge: Cambridge University Press.

Ross, Don. 2011. Estranged parents and a schizophrenic child: choice in economics, psychology, and neuroeconomics. Journal of Economic Methodology, 18 (3): 215-229.

Ross, Don. 2012. The economic agent: not human, but important. In Handbook of the philosophy of science, volume 13: philosophy of economics, ed. Uskali Mäki. Amsterdam: Elsevier, 691-735.

Ross, Don, James Ladyman, and Harold Kincaid (eds.). 2013. Scientific metaphysics. Oxford: Oxford University Press.

Harold Kincaid is professor of economics at the University of Cape Town and director of the Research Unit for Behavioural Economics and Neuroeconomics (RUBEN). He is co-editor of The Oxford handbook of 
PHILOSOPHY OF ECONOMICS / BOOK REVIEW

philosophy of economics (2009) and editor of The Oxford handbook of philosophy of social science (2012).

Contact e-mail: <harold.kincaid@uct.ac.za> 